\title{
A BNCC NO CONTEXTO DA PRÁTICA: em meio a uma pandemia, é possível pensar a educação sob outras "bases"?
}

\author{
Joelma de Sousa Lemos \\ Universidade do Estado do Rio Grande do Norte \\ Marcia Betania de Oliveira \\ Universidade do Estado do Rio Grande do Norte
}

\begin{abstract}
Resumo
Esta pesquisa investiga como a Base Nacional Comum Curricular (BNCC) está sendo produzida em/por escolas de Ensino Médio Regular do município de Aracati/CE. Com base na abordagem do ciclo de políticas de Ball e Bowe (1998), questiona uma visão estadocêntrica de constituição das políticas e entende a sua produção de forma cíclica e em múltiplos contextos. Defende que o conhecimento expresso na política de currículo precisa estar imerso em um sistema de significados para que seu sentido seja apreendido pelos sujeitos. Trata de uma pesquisa qualitativa e tem como participantes professores e gestores efetivos de duas escolas estaduais de Ensino Médio (EEM) regular, situadas no município de Aracati/CE. A produção de dados foi realizada mediante organização de três Grupos Focais para perceber, por meio do acesso a esses discursos presentes no contexto da prática, como as escolas significam/traduzem a política da BNCC. Considera que novos sentidos continuam sendo produzidos no contexto da prática em relação à BNCC e outras disputas por hegemonia estão em cena, o que impacta na política que está sendo construída por esses sujeitos nessas instituições. Questiona, por fim se: em meio a uma pandemia, é possível pensar a educação sob outras "bases"?
\end{abstract}

Palavras-chave: Políticas de Currículo, Base Nacional Comum Curricular (BNCC), Ensino Médio, Ciclo de Políticas, Contexto da prática.

\begin{abstract}
This research investigates how the National Common Curricular Base (NCCB) is being produced in / by Regular High Schools in the municipality of Aracati / CE. Based on Ball and Bowe's (1998) policy cycle approach, he questions a state-centric view of the constitution of policies and understands their production cyclically and in multiple contexts. Argues that the knowledge expressed in the curriculum policy needs to be immersed in a system of meanings so that its meaning is apprehended by the subjects. It is about a qualitative research and its participants are professors and effective managers of two state high schools (SHS) regular, located in the city of Aracati/CE. The production of data was carried out through the organization of three Focus Groups to perceive, through access to these speeches present in the context of practice, how schools mean / translate the NCCB policy. He considers that new meanings continue to be produced in the context of the practice in relation to the NCCB and other disputes for hegemony are on the scene, which impacts on the policy being built by these subjects in these institutions. Finally, he asks: amid a pandemic, is it possible to think of education on other "bases"?
\end{abstract}

Keywords: Curriculum Policies, National Common Curricular Base (NCCB), High school. Policy Cycle, Practice context. 


\section{Introdução}

Este artigo $^{1}$ problematiza a Base Nacional Comum Curricular (BNCC) e investiga ${ }^{2}$ como gestores e professores significam, no contexto da prática, a Base Nacional Comum Curricular do Ensino Médio em duas escolas públicas estaduais situadas no município de Aracati/CE. Fomos movidos pela vontade de compreender como os sujeitos atribuem sentidos a essa política, como discursos em torno da produção dessa Base circulam nas escolas, assim como os possíveis desdobramentos que produzem no currículo das unidades de ensino em pauta.

O processo de construção da Base tem pautado as discussões sobre a educação brasileira, apoiada na Constituição Federal de 1988 (Brasil, 2008) e na Lei de Diretrizes e Base da Educação Nacional de 1996 (LDBEN) (Brasil, 1996) e, mais recentemente, no Plano Nacional de Educação (PNE) (Brasil, 2014), que elegeu a BNCC como estratégia para o alcance de metas voltadas para a considerada melhoria da qualidade da Educação Básica.

Nosso estudo pretende se distanciar do binário formulação/implementação na análise das políticas educacionais, haja vista que, nessa ótica, “[...] o fazer da política permanece colocado dentro de uma concepção linear, de cima para baixo, e indiferenciada de trabalho como política nas escolas" (BALL; MAGUIRE; BRAUN, 2016, p. 16). Essa compreensão da política entende que existe um centro de poder, no qual a política é pensada e formulada, e, posteriormente, transferida para as escolas para serem postas em prática pelos seus profissionais.

Referendados pelos estudos de Ball, Maguire e Braun (2016), nesta pesquisa, concebemos política como "[...] processos discursivos, que são complexamente configurados, contextualmente mediados e institucionalmente prestados" (BALL; MAGUIRE; BRAUN, 2016, p. 13). Nesse sentido, o fato de os textos da política, como é o caso da BNCC, serem amplamente difundidos e circularem no âmbito das instituições de ensino, diz pouco sobre o que realmente é feito no seu interior em relação às políticas educacionais. Isso ocorre porque, de acordo com Lopes e Macedo (2011), a cultura que circunda as diferentes instituições e as crenças, valores e identidades dos profissionais que nelas atuam reinterpretam essas políticas e "[...] novos sentidos podem ser agregados aos diferentes conceitos” (LOPES; MACEDO, 2011, p. 248).

A política curricular, como qualquer outra, é significada pelos sujeitos por meio da cultura. Logo, os sentidos de uma BNCC não são dados a priori, mas construídos a partir dos sistemas de significação que permeiam as práticas sociais dos profissionais que fazem a escola. É com base na vivência que os professores definem currículo desta ou daquela forma (LOPES; MACEDO, 2011).

Partindo da premissa de que é através da cultura que os sujeitos constroem suas relações com o mundo, o conhecimento difundido pela política de currículo também precisa estar imerso em um sistema de significados para que seja reconhecido como válido. Lopes (2015) afirma que não há como pressupor a relevância ou não de determinados conhecimentos para os sujeitos fora dos contextos nos quais os mesmos vivem, constroem relações e produzem os sentidos que regem a própria existência. 
Neste estudo, compreendemos currículo conforme discussão apresentada por Lopes e Macedo (2011), que o concebem como uma produção cultural, por estar inserido na luta pelos diferentes significados que conferimos ao mundo; "[...] o currículo como tudo, seria cultural, na medida em que funciona como um sistema de significações dentro do qual os sentidos são produzidos pelos sujeitos" (LOPES; MACEDO, 2011, p.186). Portanto, partilhamos com as autoras a ideia de que os saberes, os sujeitos e as relações sociais não são fixos, o que justifica problematizar a política curricular de construção de uma BNCC.

O artigo está organizado em três seções. Na primeira, discutimos o Ciclo de Políticas de Stephen Ball e Richard Bowe e suas implicações para a análise de políticas educacionais. Na segunda seção problematizamos a Base Nacional Comum Curricular do Ensino Médio e sua proposta de flexibilização curricular via itinerários formativos. Por fim, apresentamos o resultado da pesquisa que realizamos no intuito de compreender como os profissionais das escolas significam, no contexto da prática, a BNCC do Ensino Médio.

A pesquisa considera que novos sentidos continuam sendo produzidos no contexto da prática em relação à BNCC e outras disputas por hegemonia estão em cena, o que impacta na política que está sendo construída por esses sujeitos nessas instituições. Assim, a proposta de flexibilização curricular para o alinhamento do currículo à BNCC e aos itinerários formativos está sendo construída a partir de movimentos de negociação, de lutas e de resistências e há um processo fluído de produção de sentidos sobre os itinerários formativos que mantêm relação com as condições de trabalho e a identificação dos docentes.

\section{O ciclo de políticas e suas implicações para a análise das políticas educacionais}

As políticas de currículo, tradicionalmente, foram analisadas mediante a separação entre elaboração e implementação, como dois momentos estanques. Essa é a tônica predominante nas análises sobre as políticas educacionais até a década de 70 do século XX. O objetivo dessa investigação das políticas, conforme Lopes e Macedo (2011), limitava-se à produção de diagnósticos e à apresentação de soluções para as políticas, portanto não havia teorização sobre a política em si, tampouco contestação às mesmas, “[...] a questão do currículo se transforma numa questão de organização. O currículo é simplesmente uma mecânica" (Silva, 2017, p. 24)

As teorias críticas de currículo, embora o associem à manutenção do status quo social trazendo ao debate questões como ideologia, reprodução e resistência, não alteram a dicotomia entre proposta e implementação na análise dessas políticas, haja vista que "[...] tais processos parecem ser identificados apenas na implementação de projetos políticos, não na própria produção desse projeto no âmbito do Estado" (LOPES; MACEDO, 2011, p. 247).

A abordagem do ciclo de políticas de Stephen Ball e Richard Bowe rompe a binário proposta/implementação na análise das políticas educacionais ao articular as dimensões macro (global, Estado) e micro (local, escola) ao processo de análise de políticas. Não se trata de advogar a supremacia entre macro e micro, mas de investigar as interações que 
ocorrem entre um e outro na trajetória da política (PAIVA; FRANGELA; DIAS, 2006). Opera em uma perspectiva relacional.

Paiva, Frangela e Dias (2006, p. 244-245, grifos das autoras), com base no pensamento de Ball $(1998,2001)$ alegam que:

[...] pensar as políticas de currículo implica considerar sua constituição para além dos movimentos verticalizados de cima para baixo, marcado pelo poder central, pelos governos, e de baixo para cima, tendo na prática seu campo de produção. Ao contrário, devemos pensá-las como um contínuo ciclo de políticas.

Ball e Bowe (1992 apud MAINARDES, 2006) partem do pressuposto de que as políticas estão em permanente movimento, pois são caracterizadas por elementos instáveis e contraditórios, suscetíveis às pressões oriundas dos grupos de interesses, às singularidades das instituições e às múltiplas interpretações, reinterpretações e traduções que os atores fazem dos textos das políticas.

Para Ball, Manguire e Braun (2016), a política é constituída de texto e discurso. O texto refere-se aos documentos oficiais, que trazem a fundamentação da política definida pelos acordos construídos. Esses textos são codificados de forma complexa pelos governos e decodificados pelos atores, também, de maneira complexa, o que permite a reformulação constante da própria política. A política como discurso envolve as disputas de poder entre os diversos grupos de interesse para a legitimação da política. Nessas disputas, alguns discursos são hegemonizados e constroem ideias e conceitos, que passam a ser aceitos pela maioria dos grupos.

Ball e Bowe (1992 apud MAINARDES, 2006) denominaram de contextos os diversos espaços nos quais esses conflitos e acordos acontecem: Contexto de Influência, Contexto de Produção de Texto, Contexto da Prática, Contexto dos Resultados e Contexto da Estratégia Política. Segundo Mainardes (2006), esses contextos não constituem etapas lineares nem uma dimensão temporal, eles estão inter-relacionados e cada um possui arenas e grupos de interesse caracterizados por disputas e embates.

Conforme apontado por Mainardes (2006), o contexto da influência é a arena na qual os discursos políticos são elaborados a partir do confronto de ideias entre os diversos grupos de interesse para a definição do discurso que servirá de base à política. Esse é o lugar de articulação de apoios para a legitimação de conceitos e soluções propostas e, concomitantemente, para as vozes que se insurgem contra determinados discursos devido à influência e à representatividade alcançadas na esfera pública. Nessa dinâmica de embates, contestações e negociações, a política vai sendo desenhada.

O segundo contexto do Ciclo de Políticas, o da produção de texto, mantém inter-relação com o contexto de influência. Nele, os discursos políticos ganham materialidade através da produção de textos normativos, base legal da política pensada. "Na produção de textos, os antagonismos, os conflitos apresentados no contexto de influência se expressam. Discursos circulam em disputas por hegemonias para representar e representar-se no texto escrito" (SANTOS; OLIVEIRA, 2013, p. 502). Dessa forma, os textos políticos corporificam os 
acordos construídos no contexto da influência e são representativos daqueles discursos que se tornaram hegemônicos na luta pelo controle das representações da política.

O contexto da prática é a arena na qual os textos da política são interpretados e recriados pelos atores locais e sofrem mudanças significativas, pois esses profissionais a partir de seus valores e experiências, da própria cultura da instituição e das condições materiais das mesmas atribuem novos significados aos textos das políticas e/ou podem rejeitar e ignorar partes dele. Concordamos com Santos e Oliveira (2013, p. 503) que:

A escola não pode ser vista apenas como receptáculo de políticas pensadas longe de sua realidade, tendo a função somente de implementar, como vítima indefesa, tudo o que fora elaborado alhures. No contexto da prática a política está sujeita à interpretação e recriação, pois ela produz efeitos e consequências que podem representar mudanças e transformações significativas na proposta política oficial.

Vale considerar que, originalmente, o Ciclo de Políticas era formado apenas pelos contextos da influência, da produção de textos e da prática. Ball, em 1994, acrescenta mais dois contextos à análise das políticas: o contexto dos resultados e o contexto das estratégias políticas. O contexto dos resultados diz respeito aos efeitos causados pelas políticas e seus impactos em relação às desigualdades existentes. Mainardes (2006) afirma que para Ball as políticas não produzem apenas resultados, geram também efeitos; portanto devem ser analisadas em suas múltiplas facetas e relacionadas às mudanças que acarretam, ou não, no meio social bem como às suas interfaces com outras políticas setoriais e com o conjunto das políticas.

O último contexto pensado por Stephen Ball foi o da estratégia política voltado para o desenvolvimento de ações sociais e de políticas necessárias para amenizar as desigualdades criadas ou reproduzidas por essas políticas. Esse contexto também é arena fundamental em embates e situações sociais específicas. Para Mainardes (2006, p. 60):

A questão essencial do contexto dos resultados/efeitos e do contexto da estratégia política é a reflexão profunda sobre questões conjunturais e sobre as desigualdades sociais que são criadas ou reproduzidas pela política ou pelo programa, e que somente podem ser detectadas pela pesquisa criteriosa do contexto da prática por meio de observações prolongadas, entrevistas ou pesquisa etnográfica $[\ldots]$.

Segundo Ball, Manguire e Braun (2016), ao analisar qualquer política, devemos nos debruçar sobre as origens do discurso da política e sobre as interpretações que são feitas dos textos que as fundamentam no contexto da prática pelos profissionais que as implementam. Para esses autores, os textos políticos são escritos para escolas ideais, por isso, necessariamente, precisam ser traduzidos do texto para a ação (prática) em contextos reais, por meio de um trabalho criativo, sofisticado e complexo de interpretação e tradução.

A interpretação é o processo de atribuição de sentido à política, de decodificá-la a partir da cultura, da história da instituição e de suas prioridades bem como da biografia dos atores 
que nelas atuam. A tradução é o processo de atuar sobre a política, transformando os textos institucionalmente significados em ação, ou seja, em práticas contextualizadas. Nesse percurso, a distância entre o texto original da política e aquele construído na prática pode ser significativa.

Essa dinâmica pelas quais as políticas passam no contexto da prática levam Ball a rechaçar a ideia de que as políticas são meramente implementadas; ao invés disso, o autor postula que elas são traduzidas. "Atuações são sempre mais do que apenas a implementação, elas reúnem dinâmicas contextuais, históricas e psicossociais em uma relação com os textos e os imperativos para produzir ação e atividades que são políticas" (BALL; MAGUIRE; BRAUN, 2016, p. 103).

\section{A BNCC do ensino médio e a proposta de flexibilização curricular via itinerários formativos}

Segundo a BNCC do Ensino Médio, o desenvolvimento tecnológico acarreta mudanças no mundo do trabalho e nas relações sociais que impactam na formação dos jovens, por isso é necessário pensar políticas curriculares que se ajustem a esse cenário "[...] cada vez mais complexo, dinâmico e fluido [...]" (BRASIL, 2018a, p. 462) e que atendam às expectativas das juventudes.

Conforme aponta o documento, esse conjunto de demandas de formação no Ensino Médio não será atendido com a organização curricular vigente, caracterizada na Base com excesso de disciplina e de abordagens pedagógicas que não respondem às expectativas dos jovens, do mundo do trabalho e da sociedade na atualidade. Diante dessa considerada inadequação curricular, a BNCC, incorporando a Reforma do Ensino Médio (Lei ${ }^{\circ}$ 13.415/2017), propõe um currículo diversificado e flexível, determinando que o mesmo seja composto pela Base Nacional Comum Curricular e por itinerários formativos (BRASIL, 2018b).

Para a BNCC, é imprescindível romper com a centralidade das disciplinas nos currículos, adotando metodologias que evidenciem "[...] a contextualização, a diversificação e a transdisciplinaridade ou outras formas de interação e articulação entre diferentes campos de saberes específicos" (Brasil, 2018c, n.p.). Entendemos, a partir de estudos de Lopes (2019), que a BNCC do Ensino Médio aponta as disciplinas escolares como simples divisão do conhecimento a serem reagrupadas, e desconsidera que elas representam instituições, organizadas em comunidades disciplinares, com as quais os sentidos da política curricular são negociados, constituindo a identidade dos docentes.

Na BNCC, os currículos do Ensino Médio são compostos pela formação geral básica e pelos itinerários formativos. A formação geral básica refere-se aos direitos e objetivos de aprendizagens, expressos em competências e habilidades fixados na BNCC. Os itinerários formativos são caracterizados na Base como estratégicos para a flexibilização curricular no Ensino Médio e englobam "[...] situações e atividades que os estudantes podem escolher [...]" (BRASIL, 2018b, p. 3) dentro das possibilidades ofertadas pelas instituições e redes de 
ensino, e têm como objetivo "aprofundar e ampliar aprendizagens em uma ou mais Áreas de Conhecimento e/ou na Formação Técnica e Profissional, com carga horária total mínima de 1.200 horas" (BRASIL, 2018b, p. 3).

Cabe às redes de ensino definir quais itinerários formativos construirão e quais eixos estruturantes serão mobilizados nos percursos definidos. Dessa forma, conforme aponta Lopes (2019, p. 67), “[...] o tão enfatizado protagonismo juvenil, associado à escolha do que estudar, torna-se submetido às possibilidades de escolas e redes, algo que [...] a juventude não tem o poder de interferir diretamente".

No guia de implementação do Novo Ensino Médio (BRASIL, 2018b) é recomendado o alinhamento dos itinerários formativos ao projeto de vida dos estudantes. Segundo a BNCC, o projeto de vida é aquilo que os estudantes almejam e projetam para si, sendo o principal canal através do qual o protagonismo juvenil é exercido no currículo dessa etapa de ensino e o eixo central em torno do qual a escola pode organizar suas práticas.

Lopes (2019) destaca que ser cidadão trabalhador é o limite da significação das singularidades humanas na BNCC, a ponto de a Base do nível médio estar submetida ao trabalho como projeto de vida, o que reitera o quanto a BNCC “[ [...] parece querer controlar o futuro dos jovens [...] via itinerários formativos, sem admitir que esse futuro - como porvir - não é algo programável ou previsível” (LOPES, 2019, p. 70).

\section{A pesquisa em cena: a BNCC e o contexto da prática}

Partimos da perspectiva de que a BNCC será lida de forma contextual nas diferentes instituições de ensino. Por isso propusemos, nessa seção, compreender como os profissionais das escolas lócus dessa pesquisa significam no contexto da prática a Base Nacional Comum Curricular. Entendemos, assim, que os sentidos de uma política não são dados a priori, mas que existe uma complexa teia de relações que medeiam a construção desses sentidos. "Na prática, as escolas são constituídas de diferentes tipos, de diferentes gerações, de professores com diferentes disposições em relação ao ensino e à aprendizagem, fixados dentro de diferentes ondas de inovação e mudança" (BALL; MAGUIRE; BRAUN, 2016, p. 18), e esses aspectos possibilitam a significação dos textos políticos de formas diversas.

\subsection{Questões metodológicas da pesquisa}

Este estudo elegeu a pesquisa qualitativa, de natureza interpretativa, como modalidade de abordagem metodológica. A pesquisa teve como participantes professores e gestores efetivos de duas Escolas de Ensino Médio (EEM) regulares, pertencentes à rede pública do Estado do Ceará, no município de Aracati. A opção por essas escolas justificou-se por se localizarem na cidade lócus da pesquisa e por pertencerem a níveis diferentes de acordo com a classificação dos estabelecimentos de ensino público do Estado do Ceará.

Uma das escolas da pesquisa é tipificada pela SEDUC/CE como de nível A, pois atendeu em 2019 um universo de 1.784 alunos. Funciona nos três turnos: manhã, tarde e noite, 
ofertando além do Ensino Médio regular a modalidade de Educação de Jovens e Adultos (EJA) e possui uma extensão na modalidade regular, ofertada no noturno, distante aproximadamente $50 \mathrm{~km}$ da sede da escola. A referida extensão funciona em uma outra escola local, de Ensino Fundamental, a partir de parceria firmada entre a SEDUC e o município de Aracati. A outra unidade de ensino da pesquisa é tipificada pela SEDUC como de nível C, com 491 alunos matriculados em 2019, funcionando nos turnos manhã e tarde. Essa diversidade vivenciada pelas escolas agregou ao nosso estudo múltiplos olhares sobre o nosso objeto de pesquisa.

A opção pelos professores e gestores efetivos como sujeitos de nossa pesquisa justificouse pelo recorte temporal da pesquisa, o ano de 2017, quando a BNCC foi aprovada pelo Conselho Nacional de Educação (CNE). O fato de esses profissionais serem do quadro permanente das instituições, aumenta a possibilidade de os mesmos terem acompanhado as discussões e os processos de construção da BNCC nas escolas ao longo desse período.

As escolas e os sujeitos da pesquisa tiveram suas identidades preservadas. Nominamos as instituições educativas de "X" e " $\mathrm{Y}$ "; os gestores da escola $\mathrm{X}$ foram alcunhados $\mathrm{A}, \mathrm{B}$ e C, enquanto os da escola $\mathrm{Y}$ denominados $\mathrm{D}$, E e F. Já os professores da escola $\mathrm{X}$, os únicos a participarem da pesquisa, foram nomeados aleatoriamente de G, H, I e J.

A produção de dados foi realizada mediante organização de três grupos focais. O grupo focal com os professores da escola $X$ ocorreu no dia 4 de outubro de 2019. O grupo focal com os gestores da escola Y aconteceu no dia 10 de dezembro de 2019 e na escola X, ocorreu em 12 de dezembro de 2019. Durante o encontro, buscamos compreender, a partir do discurso dos participantes, como os sujeitos atribuem sentidos a essa política, como esse discurso circula na escola e quais desdobramentos essa política produz no currículo das unidades de ensino.

$\mathrm{Na}$ interpretação dos discursos produzidos nos grupos focais consideramos o contexto em que as ideias foram produzidas, a reiteração pelo grupo de ideias semelhantes, as temáticas que mobilizaram os participantes e os consensos ou contradições percebidas a partir delas. Buscamos ainda ampliar nossa compreensão desses discursos mediante a triangulação com o referencial teórico da pesquisa. Na redação das análises, construímos o texto de forma a destacar as ocorrências em que as temáticas discutidas foram abordadas diretamente por nós, enquanto moderadores, e as que resultaram da interlocução entre os participantes.

\subsection{Os discursos dos docentes e dos gestores: dos limites e das possibilidades da BNCC aos sentidos de currículo}

Durante a mediação do grupo focal, perguntamos aos participantes como eles compreendiam a política de uma Base Nacional Comum Curricular no contexto de sua prática e quais as possibilidades ou limites de sua efetivação. Os gestores das escolas fizeram uma análise mais macro da política e manifestaram posições diferentes em relação à compreensão da mesma. Para os gestores da escola X, a BNCC segue os padrões da educação americana, 
não valoriza a realidade brasileira, sendo necessário haver a ressignificação dessa Base, para não se perder a questão conceitual de currículo, pois este é identidade.

Toda vez que eu falo em BNCC, eu vejo a educação americana, a mesma proposta, a mesma ideia, o aluno escolhe as disciplinas, o aluno vai para a sala de aula que ele mais se sente bem; ou seja, para mim, ainda, é alguma coisa pautada em outras coisas que estão vindo por fora, mas ainda não pensa no Brasil, Brasil em si (GESTOR C, ESCOLA X, 2019).

A BNCC tem que ser agregada a ressignificação desse currículo para cada local, porque quando você generaliza tudo e diz nós 'vamos aprender isso na Base Comum' e não sistematiza que tem que haver uma significação desse currículo; que esse currículo tem que ser flexível de acordo com a localidade em que ele vai ser construído, perde-se também a questão conceitual de currículo. Currículo é identidade (GESTOR B, ESCOLA X, 2019).

Na compreensão dos gestores da escola Y, a BNCC é um documento bem desenhado e representa um crescimento para a educação brasileira; e, caso seja implantado de forma orgânica da Educação Infantil ao Ensino Médio contribuirá para a superação dos problemas que enfrentamos atualmente. Acrescentaram, ainda, que a Base traz equidade à educação brasileira, ao propor uma orientação curricular para todas as etapas da Educação Básica e definir critérios para as avaliações externas.

Qualquer orientação curricular está para proporcionar exatamente a equidade, proporcionar a igualdade de ensino, para que haja uma orientação curricular importante, necessária, básica para as escolas nos mais diversos níveis. [...]. Se não há Base não tem como a gente fazer a aplicação da equidade, da igualdade de ensino, assim como também qualquer avaliação externa é obsoleta, não tem fundamento. Sem objetivo não há fundamento para uma avaliação externa (GESTOR E, ESCOLA Y, 2019).

A Base é um documento muito bem desenhado, representa um crescimento mesmo, um desenvolvimento não só da competência cognitiva, mas das competências como um todo. Então, se, lá na base, as políticas municipais tiverem esse cuidado desde a Educação Infantil, quando esse menino chegar ao Ensino Médio, não vamos estar enfrentando os problemas que enfrentamos hoje (GESTOR D, ESCOLA Y, 2019).

Os gestores da escola $\mathrm{Y}$ apresentaram um discurso que se tornou hegemônico na sociedade brasileira em relação à Base, sendo inclusive fortemente influenciado pelo texto do próprio documento. Logo, externaram uma visão positiva dessa política que, na visão deles, parece representar um salto de qualidade para a educação brasileira. Tivemos a impressão de que, embora não se mostrem contrários à BNCC, os gestores da escola $\mathrm{X}$ 
relativizaram a importância da Base na superação dos desafios enfrentados pela nossa educação, destacando aspectos da política que precisam ser aperfeiçoados.

Ao nosso ver, quando se posicionaram em relação às possibilidades ou limites de efetivação da proposta da Base, os gestores corroboram com a interpretação que realizamos acima. Nas palavras dos gestores da escola X, destacamos: "É necessário ressignificar esse currículo, essa Base de acordo com a identidade de cada região. Nós somos um país continental, com culturas muito diferentes [...]" (GESTOR B, ESCOLA X, 2019). "Eu acho importante pensar exatamente nessa Base, mas que ela seja a raiz e aos poucos possa se ramificar dando voz aquilo que a gente tem de identidade nesse ambiente. Então, se ela não propõe isso, a escola se robotiza [...]" (GESTOR C, ESCOLA X, 2019).

Para a gestão da escola $\mathrm{Y}$, "O grande desafio mesmo vai ser o professor modificar a sua forma de ensinar. Ele é professor de Língua Portuguesa, mas vai ter que ensinar um itinerário que de forma interdisciplinar, está associado a outra área [...]" (GESTOR F, ESCOLA Y, 2019). "Às vezes, temos propostas inovadoras e lá na sala de aula, no chão da escola, a política acontece da forma mais tradicional possível; não acontece" (GESTOR D, ESCOLA Y, 2019).

Na nossa visão, a escola Y potencializa ainda mais o seu discurso em prol da Base apontando a prática pedagógica dos professores como limite para a sua efetivação. Inferimos a partir do discurso dos gestores a concepção de que outras políticas de currículo consideradas tão inovadoras quanto a própria Base, fracassam em decorrência do ensino, ou seja, o problema não está na concepção da política em si, mas no ensino presente nas escolas. A escola X continua problematizando a política e apontando aspectos que possam aperfeiçoála, como a necessidade de adequar a Base à cultura de cada região e às várias juventudes existentes nas escolas.

Por sua vez, os professores, quando responderam a essa mesma pergunta, destacaram questões da política diretamente relacionadas ao exercício da docência, apontando contrapontos ao discurso da Base. No discurso deles, a BNCC retira a autonomia do professor, distancia o ensino de uma relação humana e privilegia conteúdos que podem não ter significados para a vida dos alunos. "Se vem definido o que eu tenho que dar, o que eu tenho que fazer, como deve ser a minha prática em sala de aula, isso aí tira a autonomia do professor [...]" (PROFESSOR J, ESCOLA X, 2019). "Uma BNCC nessa ótica que estamos percebendo aqui na maioria como controladora, [...] como vai distanciar daquela relação humana, daquela interação afetiva, e mais na construção de cobrança dos conteúdos" (PROFESSOR G, ESCOLA X, 2019). "[...] e quanto aos alunos? [...] foi perguntado o que eles esperam da vida escolar deles, o que eles de fato querem construir como conhecimento? Será que eles estão preparados para isso? Eles querem isso mesmo?" (PROFESSOR I, ESCOLA X, 2019).

Em relação às possibilidades e aos limites da Base, os docentes questionaram o perfil de cidadãos e profissionais que resultará dessa política e apontaram que a Base não é um currículo voltado para desenvolver o senso crítico do aluno, mas sim para melhorar o desempenho do Brasil nas avaliações externas e formar o jovem trabalhador para o mercado de trabalho. "Não é um currículo para questão de formar para cidadania, desenvolver o senso 
crítico do aluno. É mais para atender essa questão dos organismos internacionais [...] e de trabalhar o jovem para a produção, o mercado de trabalho" (PROFESSOR J, ESCOLA X, 2019). "Acho que a cidadania e a equidade vêm para mascarar o último que é o mercado de trabalho [...]. Como eles trazem o discurso da cidadania e propõem tirar as disciplinas de humanas do currículo? (PROFESSOR I, ESCOLA X, 2019). "Estamos preparando os meninos para uma prova, mas educação não é só a prova, tem outras questões também" (PROFESSOR H, ESCOLA X, 2019).

Observamos uma análise muito coerente dos professores no que tange a uma organização curricular com base em competências como é o caso da BNCC. Conforme aponta Silva (2018, p. 11), prepondera nessas políticas “[...] uma concepção de formação humana marcada pela intenção de adequação à lógica do mercado e à adaptação à sociedade por meio de uma abstrata noção de cidadania". Ainda para a autora, a formação dos indivíduos nesse caso está voltada para interesses externos a eles, mas convenientes à lógica mercantil, o que dificulta que "[...] se tome o conhecimento como objeto de experiência que oportuniza a reflexão e a crítica" (SILVA, 2018, p. 11).

Outra questão que o discurso dos docentes aponta é um reducionismo na BNCC da ação de educar ao ensino de conteúdo. Segundo Macedo (2012) “[...] como na Base o conhecimento não é visto como prática de significação, mas como coisa, como produto sóciohistórico que, uma vez selecionado, passa a fazer parte do currículo" (MACEDO, 2012, p. 727), é que se opera essa simplificação da ação de educar à ideia de ensino, "[...] transformando a educação em mero reconhecimento, em inserção no já existente, em uma cultura já dada" (MACEDO, 2012, p. 728).

Percebemos que os professores apontaram uma visão mais crítica da política que os gestores. Tivemos a impressão de que os docentes percebem a Base como mais uma política que chega à escola entre tantas outras já propostas, relativizando um pouco o seu impacto na educação brasileira. Quando dizem que o foco são os conteúdos, o mercado de trabalho e a necessidade de oferecer respostas aos organismos internacionais, estão inferindo que outras políticas também já perseguiram esses propósitos; ou seja, na nossa compreensão, eles reagiram diante da política de forma menos apaixonada que os gestores.

Essa nossa percepção também é corroborada por algumas falas que associam a BNCC a propostas curriculares como a dos Parâmetros Curriculares Nacionais (PCN) e caracterizamna como uma política que agrega orientações anteriores, porém com a possibilidade de exercer maior controle sobre a prática dos docentes. "É como se pegasse uma junção de todos os documentos que já têm e ficasse num só, na BNCC, mas agora com um controle maior sobre a prática do professor" (PROFESSOR H, ESCOLA X, 2019). "Na realidade o que é que vai mudar na vida da gente? Porque eles determinam os conteúdos comuns e os diversificados. Nós trabalhamos hoje com conteúdos comuns e diversificados; os parâmetros dizem isso. (PROFESSOR J, ESCOLA X, 2019)

Quando realizamos o grupo focal, as escolas da pesquisa estavam em processo de elaboração da Proposta de Flexibilização Curricular (PFC) alinhada à BNCC e aos referenciais Curriculares para a Elaboração dos Itinerários Formativos de seus ${ }^{3}$ currículos. 
Durante o grupo focal, ao manifestarem suas percepções sobre a construção da PFC nas escolas, os participantes produziram discursos com acentuado sentido de insegurança, ansiedade, angústia por não se sentirem preparados para a mediação desse processo. Para os gestores da escola X: "nós temos muita coisa para dar conta em termos de competências e habilidades em pouco tempo, em 1800 horas" (GESTOR A, ESCOLA X, 2019); "existe uma grande dúvida em torno dessa questão do itinerário formativo, porque temos a impressão de que o aluno vai escolher, mas a escola vai oferecer determinados itinerários, em determinados modelos" (GESTOR B, ESCOLA X, 2019).

Nesse mesmo sentido, os participantes da escola Y alegaram: "não sabemos qual vai ser o caminho que o Ceará vai seguir, pois está tudo ainda muito nebuloso para a gente" (GESTOR F, ESCOLA Y, 2019); "tem esse receio de redução de carga horária para determinadas áreas, está todo mundo questionando como vai ser esse novo desenho [curricular]" (GESTOR D, ESCOLA Y, 2019).

Compreendemos que essas tensões percebidas no discurso dos gestores mantêm relação com o próprio contexto em que ele está sendo produzido, quando as questões relacionadas a essa flexibilização curricular ainda são muito recentes. Ademais, a própria maneira como esse currículo foi desenhado, via medida provisória, sem qualquer discussão com a sociedade e, posteriormente, incorporado à Base, ao nosso ver, potencializa esse discurso. É possível perceber isso na fala da gestora da escola $\mathrm{X}$ ao afirmar que "os professores não se reconhecem nessa proposta de flexibilização curricular do Ensino Médio" (GESTOR B, ESCOLA X, 2019).

Nesse processo de construção da PFC, a demanda por formação foi muito presente no discurso dos participantes. Os gestores da escola $\mathrm{X}$ alegaram que as orientações do Ministério da Educação são muito superficiais "[...] nós não tivemos um suporte teórico que nos tenha dado uma fundamentação, uma segurança por onde nós trilharemos esse novo" (GESTOR B, ESCOLA X, 2019); “eu senti muita falta desse processo de formação nesse momento (...) ninguém veio aqui e juntou todo mundo e [disse] vamos treinar vocês ou vamos capacitar vocês" (GESTOR C, ESCOLA X, 2019).

Os professores da referida instituição, por sua vez, alegaram que tiveram várias discussões informais sobre a BNCC na sala dos professores, durante o intervalo, na hora do café, mas não houve uma discussão formal: "eu não participei de nenhuma discussão com fundamentação teórica, com embasamento nos documentos" (PROFESSOR H, ESCOLA X, 2019); "diante de uma política que se propõe a mudar a vida de uma escola e a vida do professor, eu acho que isso era para ser pauta de discussão dentro das reuniões de área" (PROFESSOR J, ESCOLA X, 2019)

Os gestores da escola Y perceberam essa falta de formação como uma falha do processo e destacaram que a "gestão não teve uma formação ainda a respeito da Base, do Novo Ensino Médio, dos itinerários, para que pudéssemos replicar junto aos professores" (GESTOR F, ESCOLA Y, 2019); "a maior preocupação que eu vejo é como isso vai se concretizar, como é que isso vai ser. É mais a parte prática do que a teórica” (GESTOR D, ESCOLA Y, 2019).

Significantes como "trilho", "treino", "replicar" e "prática", dentre outros, presentes nas falas dos gestores, sugerem sentidos de uma formação voltada à operacionalização dessa 
proposta e não à compreensão das implicações dessa política para a educação, para o ensino e para o próprio currículo; ou seja, o papel da escola é entendido nessas falas como o de implementar a política formulada em outros espaços. A perspectiva do Ciclo de Políticas de Ball, em especial em nossa investigação, é tentar romper com esse binário formulação/implementação na compreensão das políticas, haja vista que nessa ótica existe um centro de poder, no qual a política é pensada e formulada, sendo transferida para as escolas para serem "postas em prática" pelos seus profissionais.

Os gestores perceberam resistências e conflitos por parte dos docentes nesse processo de elaboração da PFC. Destacaram aspectos voltados à lotação, dado o receio dos professores de perderem carga horária nesse novo desenho curricular; aos recursos financeiros disponíveis para a execução da proposta; à infraestrutura da escola, questionando como essas mudanças propostas seriam acomodadas no espaço que a escola dispõe. "Qual vai ser a estrutura que nós vamos ter, qual a programação que nós vamos ter, quais as capacitações que nós iremos ter para a gente viver essa nova realidade?" (PROFESSOR I, ESCOLA X, 2019). "Se nós estamos vivendo esse momento de contingenciamento e temos uma política que precisa de dinheiro, como é que vai acontecer isso? É mágica?" (PROFESSOR J, ESCOLA X, 2019).

As duas escolas também enfrentaram resistências em relação à discussão sobre os itinerários formativos. A escola $\mathrm{X}$ pontuou que tiveram que observar as vocações econômicas do município, os interesses e necessidades dos alunos e as demandas dos professores. A escola Y acrescentou como resistência o diálogo entre esses itinerários e as disciplinas escolares, alegando que isso mexe com a identidade dos professores. "Por que eu não sou professor de Matemática? [..]. Eu sou professora de Língua Portuguesa, porque eu me identifico. Não é de uma hora para outra que vou aprender novos conhecimentos [...] e contagiar meus alunos" (GESTOR E, ESCOLA Y, 2019).

Na perspectiva do Ciclo de Políticas, essas resistências e conflitos, que ocorrem no contexto da prática, possibilitam a recontextualização das políticas, pois há um novo discurso sendo produzido e novos sentidos são atribuídos à política. A recontextualização ocupa lugar central no ciclo de políticas de Ball (Lopes, 2005), uma vez que os discursos e os textos que circulam entre os diversos contextos vão sendo recontextualizados para acomodar os interesses dos grupos que participam desse processo.

Além disso, há um processo fluído de produção de sentidos sobre os itinerários formativos que mantém relação com as condições de trabalho e com a identificação dos docentes. Esses itinerários estão sendo significados no sentido de atender a essas demandas, que no momento de construção da Proposta de Flexibilização Curricular, apresentam-se de forma muito forte para os gestores, e, contingencialmente, produz "[...] um discurso comum, provisório e contingente, no qual há fixação parcial dos sentidos possíveis de significação" (Dias; Lopes, 2009, p. 85).

Gestores e professores contestaram esse discurso de que os itinerários formativos flexibilizam o currículo do Ensino Médio. Para eles, os alunos não terão poder de escolha, vão se adequar aos itinerários formativos ofertados na escola ou no município, dependendo das parcerias estabelecidas e das possibilidades das redes de ensino. "É uma farsa dizer que 
o aluno vai escolher [...], a escola vai oferecer duas coisas para eles e eles vão se encaixar nessas duas coisas" (PROFESSOR J, ESCOLA X, 2019). "As redes [de ensino] não vão ter condições de oferecer vários itinerários. Cada escola vai acabar ofertando ao aluno o que ela achar mais possível, mais exequível de fazer e o aluno vai ter que se adequar [...]" (GESTOR B, ESCOLA X, 2019). “Aqui, no Aracati, quais são os itinerários que serão ofertados diante da realidade das três escolas? [...] o aluno vai se adequar aos itinerários que serão ofertados aqui na cidade de Aracati, conforme a realidade [...]" (GESTOR F, ESCOLA Y, 2019).

Entendemos que essa crença de que os itinerários formativos não flexibilizam o currículo do Ensino Médio está tão arraigada nos participantes que teve desdobramentos no próprio desenho da política, uma vez que as escolas não realizaram a escuta aos alunos para definir esses itinerários, elemento tido como essencial nos Referenciais Curriculares para a elaboração dos Itinerários Formativos, cujas orientações foram replicadas pela SEDUC/CE no documento encaminhado às escolas para subsidiar a construção da PFC.

Depreendemos do discurso dos gestores um certo receio em causar falsas expectativas aos discentes, haja vista que têm convicção de que não dispõem das condições objetivas para atender aos diferentes anseios que poderiam ser mobilizados mediante uma ampla consulta ao alunado. Ao nosso ver, esse é um exemplo de como as concepções dos profissionais que lidam institucionalmente com as políticas acabam por ressignificá-las.

Os gestores alegaram que a SEDUC enviou às escolas um documento para orientar esse processo de elaboração da proposta de flexibilização curricular alinhada à BNCC e aos itinerários formativos. Esse documento estava organizado por eixos e recomendava às unidades de ensino que procurassem identificar as ações já desenvolvidas pela escola, que pudessem ser encaixadas nessa proposta, inclusive com sugestões de ações implementadas na rede estadual com foco na flexibilização do currículo.

É interessante observar que o texto político que norteia as ações da PFC da escola é oriundo da SEDUC; em nenhum momento os gestores fizeram referências aos textos do MEC como os Referenciais Curriculares para a Elaboração de Itinerários Formativos ou o Guia de Implementação do Novo Ensino Médio. Como já referido anteriormente, se consideramos que, à proporção que circula entre os diversos contextos, a política é recontextualizada, e se, por outro lado, entendemos com os autores pós-estruturalistas (Lopes, Macedo, 2011), que todo texto está aberto à produção de novos sentidos, esse fato indica uma recontextualização da política já em curso.

Apesar de todos os percalços e dificuldades, os gestores acham necessária a definição de uma Base Nacional, o que aponta uma ideia de política curricular centralizada. "A BNCC vai nos indicar caminhos, para que a aprendizagem aconteça na sala de aula" (GESTOR A, ESCOLA X, 2019), "[...] é necessária nessa perspectiva de unidade, para dar uma cara à educação brasileira" (GESTOR B, ESCOLA X, 2019). Os participantes da escola Y aludiram que "a base tem uma influência, se de fato ela for concretizada da forma como está sendo orientada" (GESTOR D, ESCOLA Y, 2019), "[...] a Base vai contribuir diretamente para o ensino" (GESTOR F, ESCOLA Y, 2019). A única professora do grupo focal que se demonstrou contrária à Base, não o fez por discordar de uma política de currículo 
centralizada, mas por achar que já existem outros documentos que normatizam o currículo das escolas, como os PCNs e as DCNs.

Apesar de defenderem a regulação do currículo, os gestores da escola $\mathrm{X}$ apresentaram outras demandas que deveriam estar presentes na sua elaboração. "Eu creio que poderia ter sido diferente, pensar um pouco por dentro, para descobrir quem é esse povo, quem é esse Brasil, para poder construir essa Base" (GESTOR C, ESCOLA X, 2019); “[...] acho que definir o que é a BNCC tinha que ser feito por um processo diferente, um processo que analisasse o que o meu aluno precisa para a vida dele hoje" (GESTOR B, ESCOLA X, 2019).

Percebe-se no discurso dos gestores em defesa da BNCC, uma fala institucionalizada a partir da estreita relação apontada entre a definição de uma Base e a qualidade do ensino. Entendemos que essa homogeneidade curricular pretendida não é possível, pois a Base será sempre lida contextualmente de formas diferente, pois os textos não possuem sentidos fechados tampouco fixos e claros e, ao serem lidos, novos sentidos a ele serão sempre atribuídos (Lopes, 2017).

$\mathrm{Na}$ conclusão do grupo focal, questionamos aos participantes como eles significavam currículo. Alguns associaram currículo à seleção de conteúdos, reforçando a ideia de que alguns conhecimentos são mais válidos que outros e por isso devem constar no currículo. "O nosso currículo, que seria o oficial, é o que é visto como necessário em conteúdo, em aprendizagem para vida escolar do aluno em determinadas fases de sua vida" (PROFESSOR G, ESCOLA X, 2019). "Currículo são aqueles pré-requisitos básicos que todo aluno tem que ter numa determinada fase escolar" (PROFESSOR H, ESCOLA X, 2019). "Currículo é a união desses conhecimentos que vão ser passados, vivenciados na escola através das disciplinas de maneira isolada ou através das disciplinas de maneira interdisciplinar, transversal, enfim" (GESTOR E, ESCOLA Y, 2019). "O currículo é o princípio norteador do processo de aprendizagem. É claro que ele tem que estar fundamentado, embasado na legalidade; atualmente, a BNCC vai nortear o currículo de cada escola" (GESTOR F, ESCOLA Y, 2019).

Esses discursos apontam a necessidade de regular o currículo e por meio dele o conhecimento transmitido pela escola. Infere-se da ótica dos participantes, a ideia de que, mediante a seleção desses saberes, produz-se uma unidade, um norte para o processo ensinoaprendizagem. Conforme assevera Lopes (2017, p. 116), “[...] essa política acaba por tentar regular as possibilidades de ser dos sujeitos, os processos de identificação, sedimentando certas identidades [...]", por acreditar ser possível que o currículo possa consubstanciar um projeto de país tido como ideal e possível de ser alcançado a partir da fabricação de certas identidades via controle do conhecimento, extirpando as diferenças que constituem os sujeitos.

Subsidiados pelos estudos da referida autora, questionamos esse projeto por entendermos que toda política, incluindo a de currículo, é produto de negociações provisórias. Esse caráter contingente que a caracteriza não torna possível nem prudente universalizá-la para os distintos contextos políticos, pois " [...] a estabilidade produzida por tais decisões políticas não é apenas momentânea (ainda que esse momento possa ser 
identificado como de longa duração), mas ilusória e precária” (Lopes, 2017, p. 111, grifos da autora).

Os gestores da escola $\mathrm{X}$, embora não tenham falado explicitamente em conteúdos, produziram discursos com acentuado sentido de controle, na ideia de algo programado, planejado, para atingir um determinado objetivo, e associaram currículo ao alicerce de uma casa ou ao seu projeto de construção.

Currículo é muito importante e se você vai pensar em qualquer coisa que não seja baseada em uma proposta curricular, que seja significativa, que tenha uma concretude, que tenha uma importância, é como se você tivesse construindo uma casa sobre um alicerce em uma base de areia, vai cair, um dia (GESTOR C, ESCOLA X, 2019).

Da mesma maneira que o [...] falou da construção de uma casa, eu penso o currículo como se fosse o projeto para essa casa. Eu acho que a gente senta, a gente constrói, só que ele não se acaba ali naquele momento, porque, durante a construção, vão surgir tantas coisas que você vai querer agregar aquele ambiente, então, a escola é muito isso, é aquele dia-a-dia (GESTOR C, ESCOLA X, 2019). $\mathrm{O}$ professor, a rede [de ensino], planejaram um determinado currículo que deve ser implementado, mas o professor, quando ele operacionalizar esse currículo, tem que flexibilizar, para que ele atenda a sua demanda [...] (GESTOR A, ESCOLA X, 2019).

Entendemos que, por caminhos diversos, esses gestores endossam a concepção de currículo de seus pares. Ao compararem o currículo a alicerce, a projeto, à ideia de operacionalização e implementação, remeteram-nos à ideia de fundamento, de um centro de poder decisório, potencializando a noção de centralização da política curricular, colocando como momentos estanques elaboração e implementação. Em linhas gerais, esses discursos destacam uma concepção de currículo projetada à margem da trajetória de vida das pessoas, permanecendo "[...] a lógica de projetar a identidade do outro, supor que há um sujeito, um modo de ser/significar, uma sociedade, um modo de desenvolvimento social a ser estabilizado como melhor" (LOPES, 2017, p. 117-118).

Dois dos participantes da pesquisa produziram discursos cujos sentidos apontam uma visão mais ampla de currículo, relacionando-o a uma ação política dotada de intencionalidade.

O currículo é uma política muito importante dentro da escola; aliás, a coisa mais importante dentro da escola é o currículo. Só que o currículo foi estigmatizado muito tempo como uma grade curricular, aquela grade que tem os conteúdos, e ao fazer isso não percebemos o currículo como uma política. [...]. Temos que tirar essa ideia de currículo como grade e pensar no currículo como uma ação política, como ideológico, porque o currículo é ideológico, tem uma ideologia por trás desse currículo (PROFESSOR J, ESCOLA X, 2019). 
O currículo vai além da grade curricular, do mapa curricular; ele é uma parte disso. [...] Currículo é mesmo essa identidade da escola, as relações da escola, como ela pensa essa educação para esse aluno, que tipo de cidadão eu estou querendo formar, vai além do cognitivo, envolve todas as outras áreas do ser humano, então assim, é a essência da escola. O currículo para mim é aquilo que a escola é ou aquilo que ela demonstra ser (GESTOR D, ESCOLA Y, 2019).

Entendemos que esses participantes alargaram a compreensão do que seja currículo ao problematizarem a ideia de não neutralidade em seu processo de elaboração. Não estamos afirmando com isso que esses sujeitos entendam o conhecimento disseminado por ele como tradução, como produção de sentido, concepção por nós defendida neste trabalho, mas que, ao conceituarem currículo como uma política, compreendem a existência das lutas, dos embates e dos interesses que se desenvolvem em torno dessa ação.

\section{Considerações finais}

Esta pesquisa investigou como gestores e professores significam, no contexto da prática, a Base Nacional Comum Curricular e, ao fazê-lo, que políticas produzem nas escolas em que foi realizada. Nossa perspectiva de análise foi o Ciclo de Política de Ball, para que pudéssemos entender os movimentos de negociações, de lutas e de resistências através dos quais essa política foi sendo construída no contexto da prática pelos profissionais das unidades de ensino em pauta.

Em relação ao discurso de que a Base é uma política curricular inovadora e capaz de promover mudanças profundas na educação brasileira, dirimindo desigualdades, proporcionando equidade e aumentando a qualidade do ensino, observamos que os participantes da pesquisa também atribuem outros significados à política de definição de uma Base Nacional Comum no contexto da sua prática. Esses discursos destacam que novos sentidos continuam sendo produzidos no contexto da prática em relação a essa política e outras disputas por hegemonia estão em cena, o que impacta na política que está sendo construída por esses sujeitos nessas instituições.

Nesse sentido, constatamos que, em alguns momentos, professores e gestores apresentaram posições divergentes em relação a aspectos da política e pareceu-nos que essas disputas de significação têm mantido relação com as diferentes posições assumidas por esses profissionais no âmbito das escolas.

Pelas leituras que fizemos dos dados obtidos, veio dos professores um posicionamento mais duro, diríamos até envolto em uma espécie de ceticismo, em relação à BNCC. Na visão deles, a Base distancia o ensino de uma formação humana em sentido amplo, privilegia conteúdos dissociados da realidade dos alunos e retira a autonomia do professor. Outra questão que inferimos do discurso dos docentes foi a associação da Base a outras iniciativas curriculares que já circulam no contexto da prática e também têm como foco um maior controle sobre os conteúdos ensinados na escola, para oferecer respostas às demandas 
exigidas pelo mundo do trabalho e melhora de resultados nas avaliações externas nacionais e internacionais, o que retira o ineditismo dessa política e relativiza o seu impacto na educação.

O processo de construção da proposta de flexibilização curricular para o alinhamento do currículo dessas instituições à BNCC e aos itinerários formativos foi envolto em contestações, resistências e conflitos. Há uma fluidez de sentidos em relação aos significados desses itinerários formativos e uma tentativa de acomodar demandas voltadas às condições de trabalho e à identificação dos docentes no momento de discutir os itinerários que serão oferecidos no currículo dessas escolas. Além disso, segundo o discurso dos gestores, a construção dessa proposta está embasada nas orientações que a SEDUC/CE elaborou a partir de documentos oriundos do Ministério da Educação, o que indica uma recontextualização da política em curso. Entendemos que através dos embates que estão ocorrendo no âmbito da escola, novos sentidos a ela serão atribuídos.

Uma demanda muito presente nesse momento de construção da proposta de flexibilização curricular foi a questão da formação docente, entendida pelos participantes como necessária e cuja ausência foi significada como uma falha ao longo da trajetória da BNCC. Os gestores apontaram a inoperância do MEC em orientar as escolas nesse processo como também a ausência de formações realizadas pela própria SEDUC. Associamos essa fala dos gestores às críticas à gestão do MEC no atual governo, que apontaram a falta de coordenação das políticas educacionais no país. Por sua vez, os professores também destacaram a falta de formação em serviço sobre essa política, dado que afirmaram ter havido, apenas, discussões pontuais ou informais no âmbito das escolas.

A ideia da regulação do currículo via controle do conhecimento transmitido pela escola foi acentuada no discurso dos gestores e professores. Compreendemos que, para a maioria dos participantes de nossa investigação, existe um centro de poder decisório para o currículo, que é projetado à margem da trajetória de vida das pessoas, em uma tentativa de se alcançar um ideário de sociedade mediante projeção de determinadas identidades. Entretanto, em alguns momentos, identificamos discursos híbridos, nos quais já há uma tentativa de compreender as políticas de forma menos determinista, quando consideraram questões voltadas à valorização da cultura, às várias juventudes existentes na escola e associaram currículo à identidade.

Por força do momento que estamos vivendo, questionamos se os dados aqui destacados tivessem sido produzidos pós-pandemia, quais caminhos teriam sido apontados pela pesquisa. Afinal, quem poderia imaginar que, ao escrever as conclusões desse estudo, o mundo inteiro se encontraria de ponta à cabeça em virtude da COVID-19 ${ }^{4}$ ? Quem poderia prever que as nossas convicções, nossas crenças mais profundas estariam sendo postas em xeque diante do novo cenário que essa pandemia impõe ao planeta? Quem poderia supor que em um espaço tão curto de tempo tivéssemos que reinventar formas de trabalhar, de nos relacionar com as pessoas em virtude do distanciamento social que nos é/foi imposto como condição de sobrevivência? Quem poderá prever o mundo que resultará desse novo tempo? Aliás, será um tempo novo como alguns já especulam? 
Acreditamos que algo de novo resultará de todo esse processo. Não sabemos exatamente o quê. O momento (sempre) é de incertezas. E o que faremos com as nossas certezas diante disso? Como ficam as verdades proclamadas em propostas como a BNCC, frente ao cenário que hoje vivenciamos em meio a uma pandemia? O impacto dessas mudanças desestabilizará nossas crenças, nossas verdades absolutas, fazendo-nos perceber que não temos controle sobre o porvir? Admitiremos que para "bem educar" é necessário abrirmo-nos ao imponderável, às imprevisibilidades, às possibilidades outras que nossa razão desconhece? Pensaremos, então, a educação sobre outras "bases"?

\section{Notas}

1. Faz parte de um projeto aprovado por meio da Chamada Universal MCTIC/CNPq N. ${ }^{\circ}$ 28/2018 Universal/Faixa A (Processo n ${ }^{\circ}$ 425776-2018/2).

2. Parecer 3.590.016/2019, de 30 de agosto de 2019

3. A Portaria $\mathrm{N}^{\circ} 756$, de 03 de abril de 2019, que instituiu o Programa de Apoio à implementação da Base Nacional Comum Curricular - PROBNCC - definiu o ano de 2019 voltado à revisão ou elaboração do currículo do Ensino Médio; e 2020 para a formação continuada das redes sobre os currículos revisados ou elaborados, com previsão de bolsas de estudos e pesquisas para esses dois ciclos.

4. O nome oficial do novocoronavírus é Sars-CoV-2. Trata-se da sigla para "síndrome respiratória aguda grave por coronavírus 2" - da mesma família da Sars (Síndrome Respiratória Aguda Grave), identificada em 2002. O vírus foi detectado, inicialmente, em Wuhan, China, e reportado pela primeira vez em 31 de dezembro de 2019. A OMS declarou o novocoronavírus como emergência de saúde pública de importância internacional em 30 de janeiro de 2020. Entretanto, com a disseminação comunitária da COVID-19 em todos os continentes, a OMS passou a caracterizá-lo como pandemia em 11 de março de 2020. Para conter o avanço do vírus, a Organização recomendou três ações básicas: isolamento e tratamento dos casos identificados, testes massivos e distanciamento social de toda a população.

\section{Referências}

BALL, Stephen J; BOWE, Richard. El currículum nacional y su "puesta en práctica": el papel de los departamentos de materias o asignaturas. Revista de Estudios del Curriculum, Barcelona, v. 1, n. 2, p. 105-131, 1998.

BALL, Stephen J; MAGUIRE, Meg; BRAUN, Annette. Como as escolas fazem as políticas. Tradução de Janete Bridon. Ponta Grossa: Editora, UEPG, 2016.

BRASIL. Constituição (1988). Constituição [da] República Federativa do Brasil. Brasília: Senado Federal; Centro Gráfico, 1988. 292 p.

BRASIL. Lei n. ${ }^{\circ}$ 9.394, de 20 de dezembro de 1996. Estabelece as diretrizes e bases da educação nacional. Diário Oficial [da] República Federativa do Brasil. Brasília, DF, 20 de dezembro de 1996. Disponível em: http://www.planalto.gov.br/ccivil_03/leis/19394.htm. Acesso em: 23 jul. 2020.

BRASIL. Lei n. ${ }^{\circ}$ 13.005, de 25 de junho de 2014. Aprova o Plano Nacional de Educação e dá outras providências. Diário Oficial [da] República Federativa do Brasil. Brasília, DF, 26 de junho de 2014 Edição Extra. Disponível em: http://www.planalto.gov.br/ccivil_03/_ato2011-2014/2014/lei/113005.htm. Acesso em: 23 jul. 2020.

BRASIL. Lei n. $^{\circ}$ 13.415, de 16 de fevereiro de 2017. Altera as Leis $n{ }^{\circ} 9.394$, de 20 de dezembro de 1996, que estabelece as diretrizes e bases da educação nacional, e 11.494, de 20 de junho 2007, que regulamenta o Fundo de Manutenção e Desenvolvimento da Educação Básica e de Valorização dos Profissionais da 
Educação, a Consolidação das Leis do Trabalho - CLT, aprovada pelo Decreto-Lei $\mathrm{n}^{\circ} 5.452$, de $1^{\circ}$ de maio de 1943, e o Decreto-Lei n ${ }^{\circ} 236$, de 28 de fevereiro de 1967; revoga a Lei no 11.161, de 5 de agosto de 2005; e institui a Política de Fomento à Implementação de Escolas de Ensino Médio em Tempo Integral. Diário Oficial [da] República Federativa do Brasil. Brasília, DF, 17 de fevereiro de 2017. Disponível em: http://www.planalto.gov.br/ccivil_03/_ato2015-2018/2017/lei/113415.htm. Acesso em: 23 jul. 2020.

BRASIL. Ministério da Educação. Base Nacional Comum Curricular: Educação é a Base. Brasília: DF, 2018a. Disponível em: http://basenacionalcomum.mec.gov.br/images/BNCC_EI_EF_110518_ versaofinal_site.pdf. Acesso em: 11 nov. 2019.

BRASIL. Guia de implementação da Base nacional comum curricular: orientações para o processo de implementação da BNCC. 2018b. Disponível em: http://implementacaobncc.com.br/wpcontent/ uploads/2018/06/guia_de_implementacao_da_bncc_2018.pdf. Acesso em: 11 nov. 2019.

BRASIL. Ministério da Educação. Referenciais Curriculares para elaboração dos itinerários formativos. Brasília, DF: MEC, 2018c. Disponíveis em: http://novoensinomedio.mec.gov.br/resources/downloads/ pdf/DCEIF.pdf. Acesso em: 11 nov. 2019.

DIAS, Rosanne Evangelista; LOPES, Alice Casimiro. Sentidos da prática nas políticas de currículo para a formação de professores. Currículo sem Fronteiras, v. 9, n. 2, p. 79-99, jul./dez. 2009. Disponível em: http://www.curriculosemfronteiras.org/vol9iss2articles/dias-lopes.pdf. Acesso em: 10 jan. 2019.

LOPES, Alice Casimiro. Política de currículo: Recontextualização e Hibridismo. Currículo sem Fronteiras, v. 5, n. 2, p. 50-64, jul./dez. 2005. Disponível em: http://www.curriculosemfronteiras.org/ vol5iss2articles/lopes.pdf. Acesso: em 12 jan. 2019.

LOPES, Alice Casimiro. Por um currículo sem fundamentos. Linhas Críticas, Brasília, v. 21, n. 45, p. 445466, mai./ago. 2015. Disponível em: https://periodicos.unb.br/index.php/linhascriticas/article/view/4581. Acesso em: 08 jan. 2019.

LOPES, Alice Casimiro. Política, conhecimento e a defesa de um vazio normativo. In: MENDONÇA, Daniel de; RODRIGUES, Lio; LINHARES, Bianca (org.). Ernesto Laclau e seu legado transdisciplinar. São Paulo: Intermeios, 2017, p. 109-122.

LOPES, Alice Casimiro. Itinerários formativos na BNCC do Ensino Médio: identificações docentes e projetos de vida juvenis. Revista Retratos da Escola, Brasília, v. 13, n. 25, p. 59-75, jan./mai. 2019. Disponível em: http://retratosdaescola.emnuvens.com.br/rde/article/view/963. Acesso em: 11 nov. 2019.

LOPES, Alice Casimiro; MACEDO, Elizabeth. Teorias de Currículo. São Paulo: Cortez, 2011.

MACEDO, Elizabeth. Currículo e conhecimento: Aproximações entre educação e ensino. Cadernos de Pesquisa, São Paulo, v. 42, n. 147, p. 716-737, set./dez. 2012. Disponível em: http://www.scielo.br/pdf/cp/v42n147/04.pdf. Acesso em: 15 out. 2019.

MAINARDES, Jefferson. Abordagem do ciclo de políticas: uma contribuição para a análise de políticas educacionais. Educ. Soc., Campinas, v. 27, n. 94, p.47-69, abr. 2006. Disponível em: https://www.scielo.br/scielo.php?pid=S0101-73302006000100003\&script=sci_abstract\&tlng=pt. Acesso em: 08 jan. 2019.

PAIVA, Edil V.; FRANGELlA, Rita de Cássia Prazeres; DIAS, Rosanne Evangelista. Políticas curriculares no foco das investigações. In: LOPES, Alice Casimiro; MACEDO, Elizabeth (org.). Políticas de currículo em múltiplos contextos. São Paulo, Cortez, 2006, p. 241-269.

SANTOS, Jean Mac Cole Tavares; OLIVEIRA, Márcia Betânia de. Políticas curriculares no Ensino Médio: ressignificações no contexto escolar. Currículo sem Fronteiras. v. 13, n. 3, p. 497-513, set./dez. 2013. Disponível em: http://www.curriculosemfronteiras.org/vol13iss3articles/santos-oliveira.pdf. Acesso em: 04 mar. 2019.

SILVA, Mônica Ribeiro da. A BNCC da Reforma do Ensino Médio: o resgate de um empoeirado discurso. Educação em Revista, Belo Horizonte, v. 34, e214130, out. 2018. Disponível em: 
https://www.scielo.br/scielo.php?script=sci_abstract\&pid=S0102-46982018000100301\&lng=pt\&nrm=iso. Acesso em: 25 mai. 2020.

SILVA, Tomaz Tadeu da. Documentos de identidade: uma introdução às teorias do currículo. 3 ed. Belo Horizonte: Autêntica, 2017.

\section{Correspondência}

Joelma de Sousa Lemos: É Mestra em Educação pelo Programa de Educação em Educação (POSEDUC/UERN) (2018-2010). Licenciada em Pedagogia pela UERN (2000); Graduação em Letras,Licenciatura, com habilitação em Português e Literatura de Língua Portuguesa pela Faculdade Vale do Jaguaribe (2006); Especialização em Psicopedagogia pela Fundação Universidade Estadual Vale do Acaraú (2006);Especialização em Alfabetização pela Universidade Castelo Branco(2001). Professora efetiva do Estado do Ceará desde 2010. Membro do grupo de pesquisa Contexto e Educação (CNPq/UERN).

E-mail: solaracati@hotmail.com

Marcia Betania de Oliveira: É Professora Adjunta da Universidade do Estado do Rio Grande do Norte UERN, lotada na Faculdade de Educação. Doutora em Educação (PROPED/UERJ( (2013-2016), Mestre em Educação (PROPEG/UFRN). Graduada em Pedagogia (UERN). Membro do grupo de Pesquisa Contexto e Educação (CNPq/UERN).

E-mail: marciabetaniauern@gmail.com

Texto publicado em Currículo sem Fronteiras com autorização das autoras 